This PDF is a selection from a published volume from the National Bureau of Economic Research

Volume Title: Perspectives on the Economics of Aging

Volume Author/Editor: David A. Wise, editor

Volume Publisher: University of Chicago Press

Volume ISBN: 0-226-90305-2

Volume URL: http://www.nber.org/books/wise04-1

Conference Date: May 17-20, 2001

Publication Date: June 2004

Title: Changes in the Age Distribution of Mortality over the Twentieth Century

Author: David M. Cutler, Ellen Meara

URL: http://www.nber.org/chapters/c10348 


\title{
Changes in the Age Distribution of Mortality over the Twentieth Century
}

\author{
David M. Cutler and Ellen Meara
}

Mortality rates decline extremely rapidly in the United States over the twentieth century, as they did in all developed countries. Figure 9.1 shows the magnitude of the decline. In 1900, 1 in 42 Americans died annually. On an age-adjusted basis, the share in 1998 was 1 in 125 people, for a cumulative decline of 67 percent. Given such a substantial improvement in mortality, it is natural to ask how we achieved such gains in health and which innovations or policies contributed most to these gains.

Such a task is clearly large. One way to start is to analyze major trends in mortality over the century and to consider how mortality declines differ by age and cause of death. By providing detailed information on which demographic groups experienced the largest mortality improvements and for what causes of death, these analyses motivate hypotheses to explain the overall improvement in mortality in the twentieth century.

The mortality decline shown in figure 9.1 seems approximately linear over the time period. Mortality decreased at a relatively constant rate of 1 percent per year between 1900 and 1940. There was then a period of rapid decline from 1940 to 1955 in which mortality declined 2 percent per year, followed by essentially flat mortality rates until 1965 . Since 1965 , mortality rates have fallen at roughly 1 to 1.5 percent per year. This relative constancy of mortality decline suggests that perhaps a single factor can

David M. Cutler is professor of economics in the Department of Economics and the John F. Kennedy School of Government, Harvard University, and a research associate of the National Bureau of Economic Research. Ellen Meara is assistant professor of health economics in the Department of Health Care Policy at Harvard Medical School, and a faculty research fellow of the National Bureau of Economic Research.

We are grateful to Brian Kim and Mariko Golden for research assistance; to David Meltzer, Angus Deaton, Chris Paxson, and Anne Case for comments; and the National Institutes on Aging for research support. 


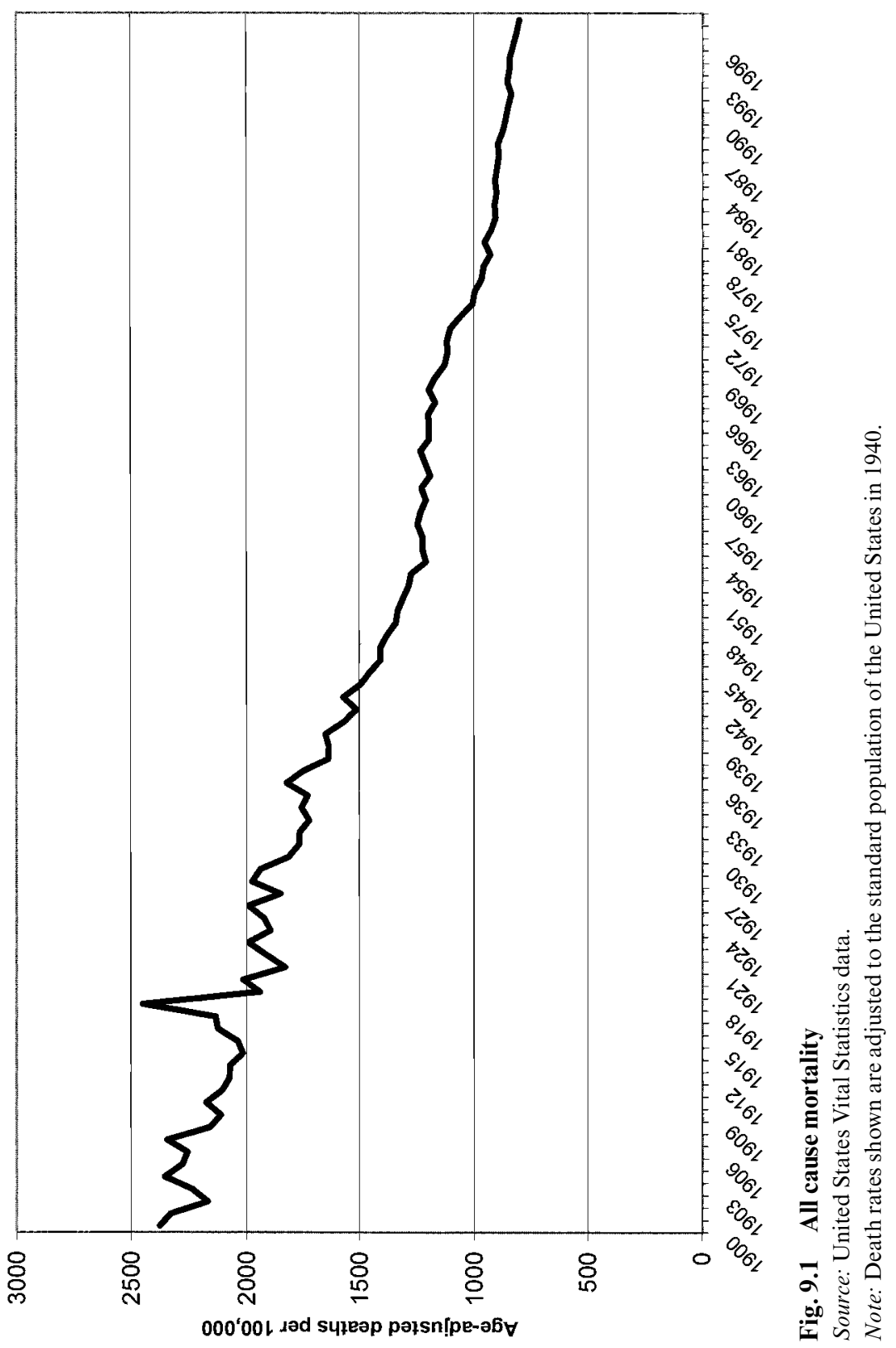


explain the trend in longer life; the popular Lee and Carter (1992) model of mortality posits a driving force of mortality that is approximately constant over time.

But the aggregate trends mask as much as they reveal. While mortality declines have been relatively continuous over the twentieth century, the age distribution of mortality decline has not. We start off the paper by highlighting a basic fact about mortality declines in the past century: Mortality reduction used to be concentrated at younger ages but is increasingly concentrated among the aged. In the first four decades of the century, 80 percent of life expectancy improvements resulted from reduced mortality for those below age forty-five, with the bulk of this for infants and children. In the next two decades, life expectancy improvements were split relatively evenly by age. In the latter four decades, about two-thirds of life expectancy improvements resulted from mortality reductions for those over age forty-five; only one-third was from the younger population.

This change has been accompanied by several important epidemiological trends. Throughout the first half of the twentieth century, infectious diseases were the leading cause of death. Changes in the ability to avoid and withstand infection were the prime factors in reduced mortality in the first part of the century. This disease-fighting ability was not predominantly medical. Nutrition (Fogel 1994) and public health measures (Preston 1996) were vastly more important in reduced mortality over this time period than were medical interventions, as substantial research documents. Nutrition and public health were particularly important for the young, and so mortality reduction was concentrated at younger ages.

Between 1940 and 1960, infectious diseases continue to decline, but was due more to medical factors. Antibiotics, including penicillin and sulfa drugs, became important contributors to mortality reduction in this era. Antibiotics help the elderly as well as the young, and so mortality reductions became more widespread across the age distribution.

Since 1960, mortality reductions have been associated with two new factors: the conquest of cardiovascular disease in the elderly, and the prevention of infant death due to low birth weight. While it is not entirely clear what factors account for the reduction in cardiovascular disease mortality, the traditional roles of nutrition, public health, and antibiotics are certainly less important. Taking their place are factors related to individual behaviors, such as smoking and diet and high-tech medical treatment. We term this change the "medicalization" of death: Increasingly, mortality reductions are attributed to medical care and not social or environmental improvements.

The medicalization of death does not imply that medicine is the only factor influencing mortality. For several important causes of death, income improvements and social programs have had and continue to have a large 
impact on mortality. For example, Medicare likely has a direct impact on mortality by increasing elderly access to medical care, but it also may have important income effects since it reduced out of pocket spending by the elderly for medical care. Social Security and civil rights programs may also be important in better health. We do not quantify the role of medicine, income, social programs, and other factors in improved mortality in the last half century, but we show examples where each is important as a first step in this research process.

The paper is structured as follows. The first section presents the basic facts about changes in the age distribution of mortality change and life expectancy improvements, highlighting the growing role of mortality reductions among the elderly. The next three sections examine why this trend has occurred, discussing in particular the epidemiology of mortality reduction at different points in time and for different causes. The fifth section then presents limited evidence on the nonmedical factors that influence mortality.

\subsection{Changes in the Age Distribution of Longer Life}

We start the analysis by summarizing changes in the age distribution of mortality improvements over time. One can summarize mortality rates in many ways. We consider a relatively simple measure: life expectancy at birth $\left[\operatorname{LE}_{0}(t)\right]$. This measure has the advantage that it weights mortality changes by how important they are to overall survival. Mortality reductions in an age range where few people die will not contribute as much to improvements in life expectancy at birth as mortality reductions in an age range where there are more deaths.

Because it is helpful for our analysis, let us be more precise about the measure. Consider a cohort of people born in year $t$. At age 0 , the share of people who die is $p(0, t)$. Suppose the initial population had $S(0, t)$ people. The number of people alive at the end of year $t$ and entering next year is $S(1, t+1)=S(0, t) \cdot[1-p(0, t)]$. To forecast life expectancy, we need to forecast the share of people who will die in year $t+1$, at age 1 , and more generally the share of people who will die at age $a$, in year $t+a$. Following standard conventions, we use a period life table and assume that the probability of death at any age $a$ in the future will be equal to the probability of death of people aged $a$ in year $t$, or $p(a, t+a)=p(a, t)$. This estimate is static; it assumes no change in mortality in the future. Although this is not the best forecasting technique - mortality rates have fallen over time - it is appropriate for our purposes of decomposing changes over time.

People who die at age $a$ are assumed to have died halfway through the year. Thus, life expectancy for a person dying at age $a$ is $a-1 / 2$. Adding across all possible ages of death, up to maximum longevity $T$, life expectancy at birth is then 


$$
\mathrm{LE}_{0}(t)=\sum_{a=0}^{T} p(a, t) \cdot S(a-1, t) \cdot\left(\frac{a-1}{2}\right),
$$

where

$$
S(a, t)=S(0, t) \cdot \prod_{s=0}^{a-1}[1-p(s, t)],
$$

and for simplicity, we assume that the cohort, $S(0, t)$, equals 1 .

Figure 9.2 shows life expectancy at birth in the United States in the twentieth century. In 1900, the average infant could expect to live forty-eight years. By the end of the century, life expectancy was near eighty years.

We want to understand how changes in mortality at different ages contribute to overall life expectancy improvements. To do this, we compare $t$ with another year $t^{\prime}$. If we substitute $t^{\prime}$ for $t$ in equations (1) and (2), equation (1) will give us life expectancy at birth in year $t^{\prime}$. But we can also substitute selectively. For example, suppose we replace $p(a, t)$ with $p\left(a, t^{\prime}\right)$ just for the elderly. We denote $p^{\prime}(a, t)$ as the new mortality probability at any age. Life expectancy at birth is then

$$
\operatorname{LE}_{0}^{\prime}(t)=\sum_{a=0}^{T} p^{\prime}(a, t) \cdot S^{\prime}(a-1, t) \cdot\left(\frac{a-1}{2}\right),
$$

where $S^{\prime}(a-1, t)$ is defined analogously to equation (2), substituting $p^{\prime}(a$, $t)$ for $p(a, t)$. The difference between equations (3) and (1), $\mathrm{LE}_{0}^{\prime}(t)-\mathrm{LE}_{0}(t)$ is the effect of mortality changes between $t$ and $t^{\prime}$ on overall years of life expectancy at birth.

If we estimate equation (3), replacing different age groups sequentially and then add up the life expectancy improvements attributable to each age group, the resulting improvement in life expectancy will be close to, but not exactly the same as, the effect of considering changes for all age groups together. The reason for the discrepancy has to do with the covariance of benefits from mortality reduction at different ages. Saving more babies has a greater impact on life expectancy at birth when the elderly also live longer than when elderly mortality is assumed constant, because more people reach their older years as infant mortality falls and thus benefit from the improvements in elderly mortality. We group the covariance effects between mortality reductions in different age groups into one term.

We estimate equations (1) through (3) empirically by considering mortality changes for five groups in the population: infant mortality $(<\mathrm{one})$; child mortality (one-fourteen); young adult mortality (fifteen-forty-four); older adult mortality (forty-five-sixty-four); and elderly mortality (sixtyfive + ). We consider the impact of mortality changes in each of these age groups over three time periods: $1900-40 ; 1940-60$; and 1960-90. The reason for choosing these time periods will become apparent later. Thus, our first estimate is how much of the overall improvement in life expectancy at 


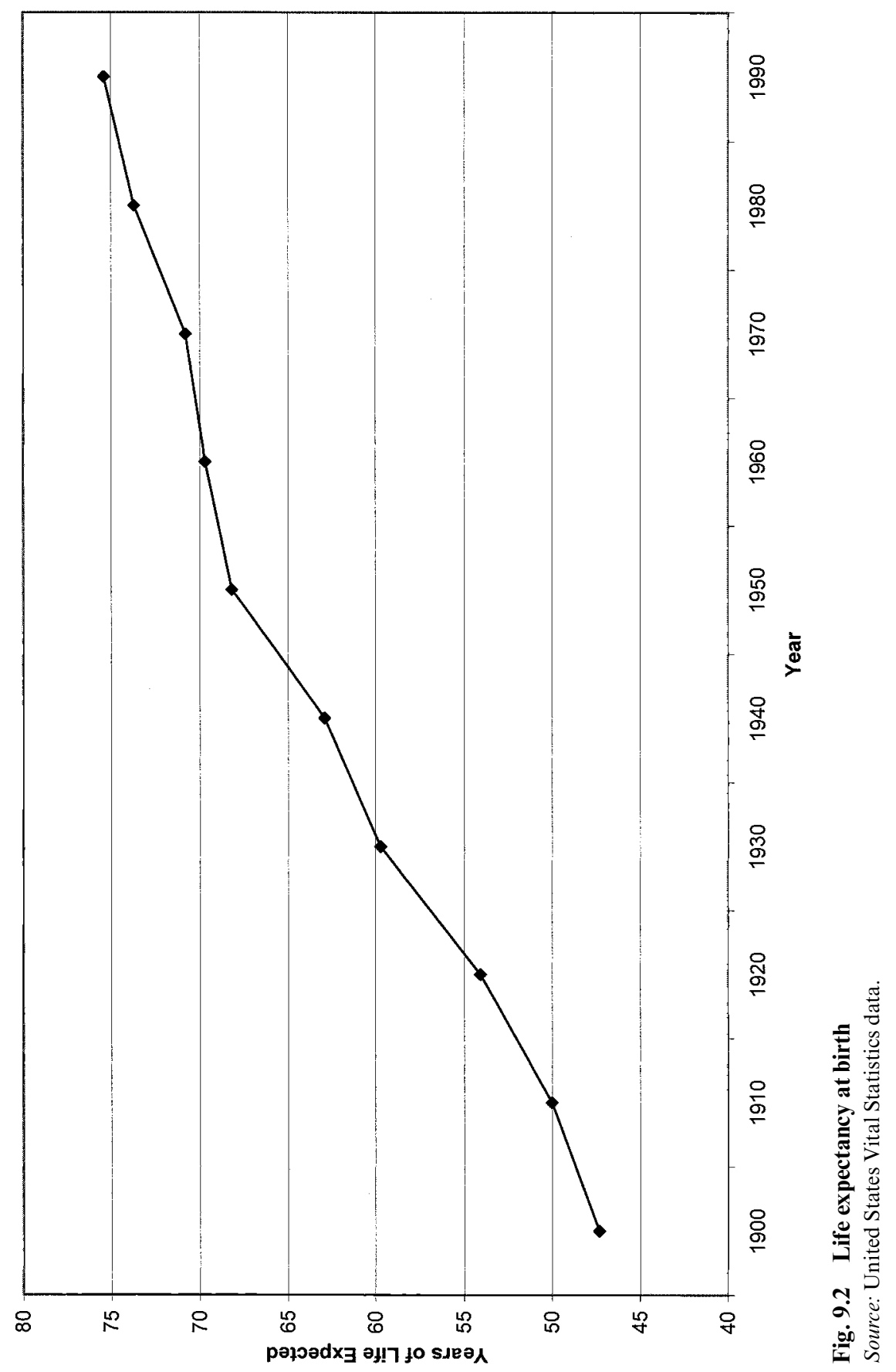


birth between 1900 and 1940 is a function of reduced mortality for each of those five age groups and so on for the different time periods.

Figure 9.3 and table 9.1 show the results. Throughout the paper, total mortality estimates are age-adjusted to the 1990 population age distribution unless otherwise noted. Our results are not sensitive to our choice to age-adjust based on the 1990 population. The first bars of figure 9.3 and column (1) of table 9.1 shows the contributors to life expectancy improvements at birth in the 1900-40 time period; the second bars and column are for the 1940-60 time period; and the third bars and column are for the 1960-90 time period. In the 1900-40 era, life expectancy improvements were concentrated at younger ages. Reduced infant mortality, for example, contributed 4 and a half years to overall improvements in life expectancy. Reduced child mortality contributed nearly as much, and reduced young adult mortality contributed about 3 and a half years. Together, these three changes account for nearly thirteen of the sixteen-year increase in expected longevity. Mortality reductions among older adults and the elderly, in contrast, explain just 1 and a half years of increased longevity combined. About 80 percent of longevity improvements, therefore, are attributable to reduced mortality among the under-forty-five population.

The next bars of the figure and column of the table are for the two decades in the middle of the century, 1940-60. The overall improvement in life expectancy at birth is smaller in this time period than in the 1900-40 time period. The change between 1940 and 1960, for example, is 6.4 years, compared to 15.9 years in the previous four decades. Part of the smaller improvement is due to the fact that the time interval is only half as large, but that is not all of the explanation.

More important for our analysis, the contribution of mortality declines at different ages to overall improvements in life expectancy is very different from the earlier time period. In the 1940-60 time period, the different age groups all contributed roughly equally to improvements in life expectancy at birth. The effect of mortality reductions in each age group is about 1 to 1 and a half years of additional life. Only 60 percent of overall improvements resulted from reduced mortality among the under-forty-five population; 35 percent is from the older population.

The third bars and last column of the table show the results for the 196090 time period. Once again, the situation changed greatly. Infant mortality was still an important source of increased longevity in the latter three decades, but child and young adult mortality were substantially less important. Taking their place were older adult and elderly mortality reductions. Reduced mortality among older adults and the elderly contributed in total about three years to overall improvements in life expectancy at birth. Changes in mortality for these age groups explain two-thirds of the overall improvement in life expectancy at birth. 


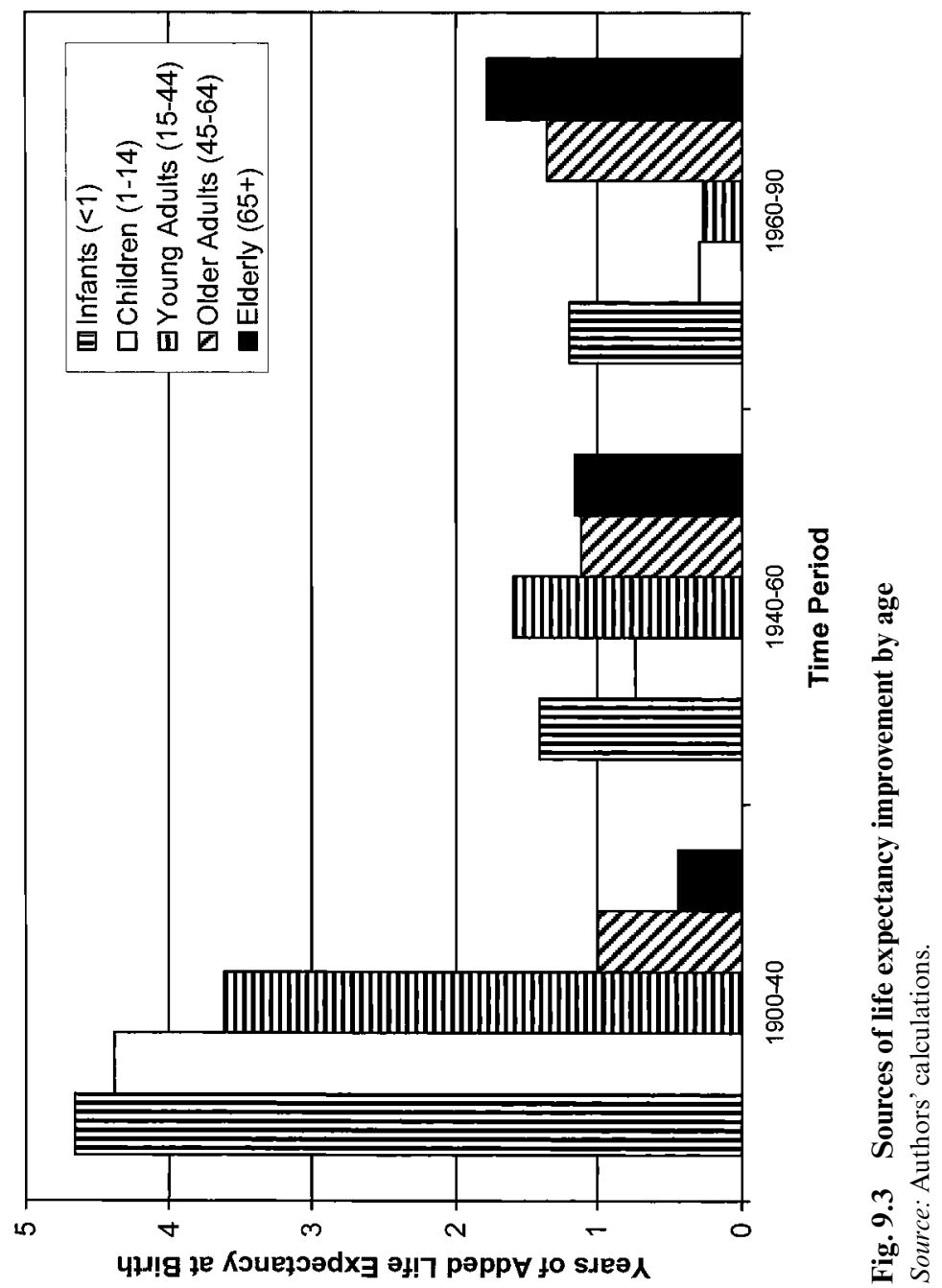


Table 9.1

Contributions to Life Expectancy at Birth

\begin{tabular}{lccc}
\hline Change in Life Expectancy at Birth & $1900-1940$ & $1940-1960$ & $1960-1990$ \\
\hline Total change (\%) & 15.9 & 6.4 & 5.1 \\
Change attributable to: & & & \\
$\quad$ Infant mortality (<1) & 4.7 & 1.4 & 1.2 \\
Child mortality (1-14) & 4.4 & 0.7 & 0.3 \\
Young adult mortality (15-44) & 3.6 & 1.6 & 0.3 \\
Older adult mortality (45-64) & 1.0 & 1.1 & 1.4 \\
Elderly mortality (65+) & 0.4 & 1.2 & 1.8 \\
Covariance terms & 1.8 & 0.4 & 0.1 \\
\hline
\end{tabular}

Notes: The text describes the decomposition. Ages in parentheses.

The greater relative contribution of mortality reductions for the older population in the post- 1960 period can be explained by two factors. The first is that mortality reductions for the elderly were more rapid in the later time period than in the earlier one. Figure 9.4 and table 9.2 shows the annual rate of decline in mortality for the different population groups. Where mortality among the elderly declined by only 0.3 percent per year between 1900 and 1940, mortality declined by 1.1 percent per year after 1960 .

The second explanation is that overall mortality rates among the young were already very low by 1960 so that even large continued increases in the rate of decline translated into much smaller changes in the absolute level of mortality. Compared to 1900 , mortality among infants was only 15 percent as high in 1960. Even when mortality rates for infants continued to decline at their pre-1960 level, as table 9.2 shows, the absolute changes corresponding to these declines were much smaller. By 1960, 70 percent of infants were already surviving to age sixty-five; this share could not increase that rapidly in subsequent generations. ${ }^{1}$

For both of these reasons, the nature of longevity improvements shifted over time. Where longevity improvements were concentrated at younger ages early in the century, they were increasingly pronounced among the elderly in the latter decades. Overall survival still increased, but the timing of those changes was very different.

1. This fact leads to a third potential explanation for the shift in longevity improvements toward the elderly, but one that is not empirically so consequential. Since the probability that an infant survived to older ages was greater in 1960 than in 1900, the same reduction in mortality rates for the elderly would have a larger impact on life expectancy at birth in the later time period. But the dominant factor in the increased contribution of mortality declines among the elderly is the more rapid reduction in mortality rates for the elderly, not the increased survival to older ages. 


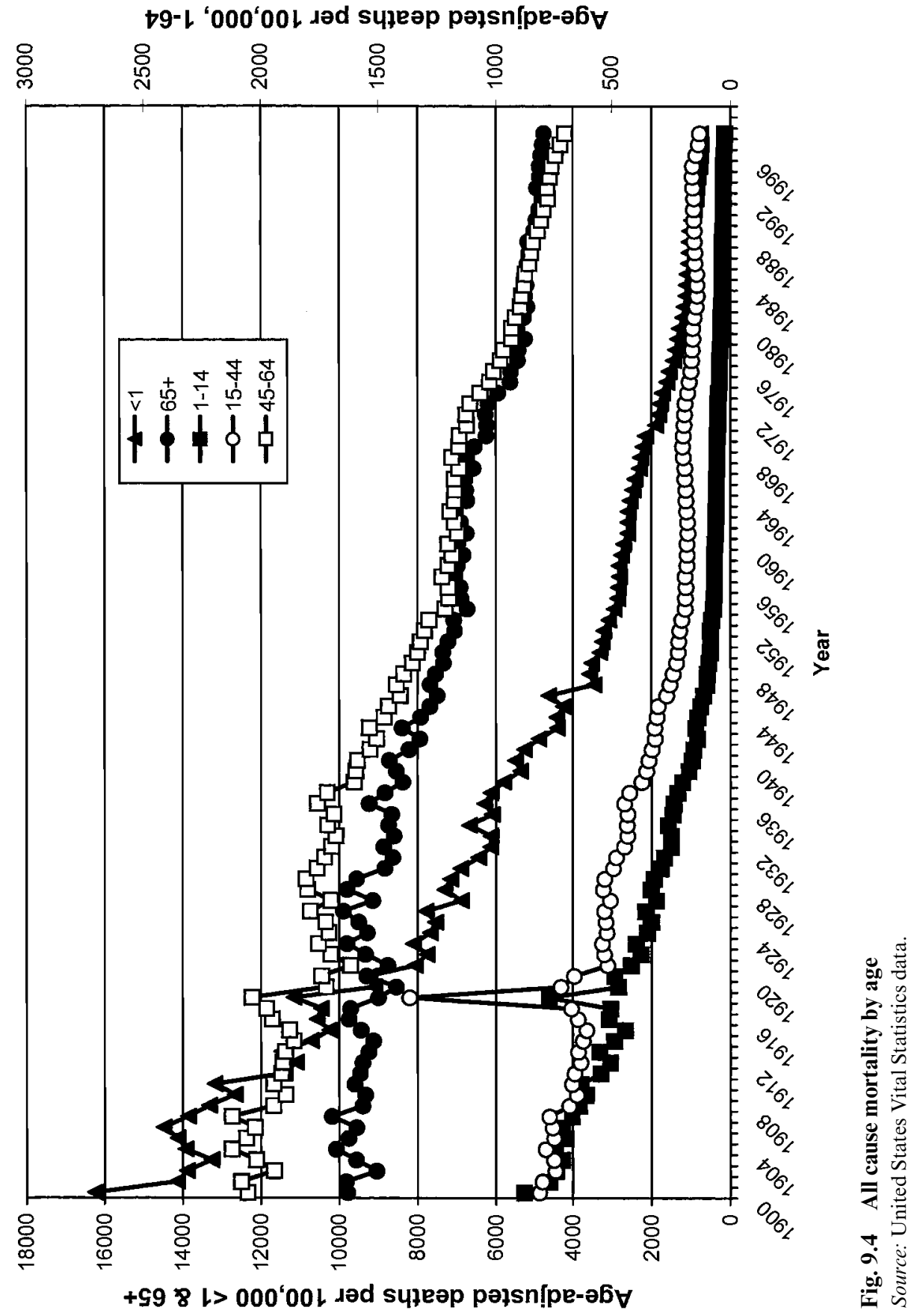


Table 9.2

Change in Mortality Rates, by Age (annual rate of decline for each age group)

\begin{tabular}{lccc}
\hline Age Groups & $1900-1940$ & $1940-1960$ & $1960-1990$ \\
\hline Total change (\%) & 0.9 & 1.5 & 1.2 \\
Decline by age: & & & \\
$\quad$ Infant mortality (<1) & 2.7 & 3.5 & 3.3 \\
Child mortality (1-14) & 4.2 & 4.4 & 2.5 \\
Young adult mortality (15-44) & 2.1 & 3.1 & 0.6 \\
Older adult mortality (45-64) & 0.6 & 1.4 & 1.3 \\
Elderly mortality (65+) & 0.3 & 1.1 & 1.1 \\
\hline
\end{tabular}

\subsection{The First Four Decades: Public Health and Nutrition}

Our goal in the next several sections is to understand why longevity improvements have shifted towards the elderly. There are two ways to understand this. The first is at the epidemiological level — what factors about mortality changed over the twentieth century that led to the shifting pattern of mortality decline? The second level of understanding is at the economic and social level-what is the underlying reason for the change in those causes of death?

An example illustrates the difference. Since the late eighteenth century, mortality rates have been declining in most developed countries. The cause of this is reduced death from infectious disease. That is the basic epidemiological fact. But the real issue is why infectious disease mortality declined. Was it improved nutrition that allowed people to avoid and withstand infections better, public health measures that reduced the spread of diseases, or did diseases become less virulent? The latter questions are the subject of substantial research in historical demography and are the ultimate object of interest.

We do not answer the questions we ask at the detailed level. Indeed, it has taken decades of work to distinguish between public health, nutritional, and medical explanations for mortality reductions over the course of the eighteenth and nineteenth centuries, so attempting such an analysis here for the twentieth century would be an act of supreme hubris. Rather, we concentrate first on the epidemiology of changes in the mortality distribution and use that to suggest hypotheses about why they are occurring. Even this is difficult, though. Cause of death changes over time, as does physician coding. It is not possible to put together an entirely consistent mortality record over time. We present here what is most readily comparable and save less comparable data for future analysis.

A first way to approach the sources of mortality reduction is to look at what causes of death declined most rapidly over time. Table 9.3 shows information on this. The rows of the table show the various causes of death. 


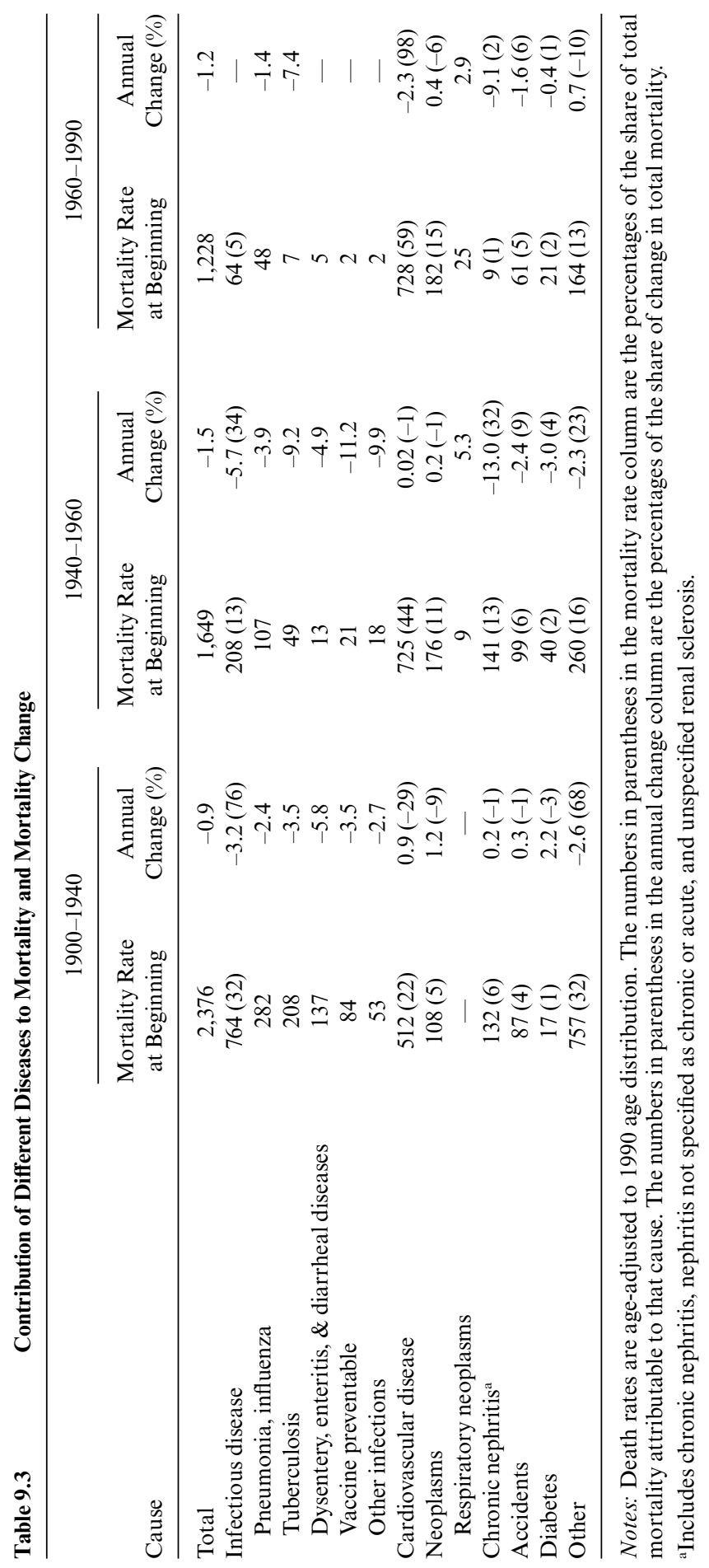


The columns are the different time periods. In each case, we report mortality rates at the beginning of the sample and the annual change in mortality rates attributable to that cause. We separate these changes into the three time periods analyzed previously: 1900-40, 1940-60, and 1960-90.

Infectious diseases were the leading causes of death in 1900. Together, infectious diseases accounted for 32 percent of total deaths. Pneumonia and influenza were the biggest killers, accounting for 12 percent of total deaths by themselves. Tuberculosis was also important, and to a lesser extent dysentery, enteritis, diarrheal diseases, and diseases where vaccinations are today possible. The leading killers of today-cardiovascular disease and cancer-together accounted for fewer deaths than infectious diseases in 1900.

Infectious diseases also saw the most rapid mortality declines in the $1900-40$ period. Deaths from pneumonia and influenza fell by 2.4 percent annually between 1900 and 1940. Deaths from tuberculosis and vaccinepreventable illness both fell 3 to 6 percent annually. In total, reduced death from infectious diseases accounts for three-quarters of total mortality reduction in this period. Figures 9.5, 9.6, and 9.7 show mortality from pneumonia and influenza, tuberculosis, and vaccine-amenable conditions graphically. Death from all of these causes was falling markedly throughout the time period.

The figures make another important point-most of the mortality reductions for these conditions occurred well before the first medical treatment was available. Pneumonia and influenza are mostly treated with penicillin, and before that with sulfa drugs. But sulfa drugs were discovered in 1935, and essentially all of the decline in pneumonia- and influenzaattributable deaths occurred well before sulfa drugs were available. Tuberculosis mortality fell long before antituberculosis drugs came into use in the mid-1940s. And vaccine-preventable deaths declined well before there were vaccines.

We are by no means the first to notice this finding. Thomas McKeown (1976) and McKeown, Record, and Turner (1975) first brought the issue to prominence, and it has been a well-recognized fact ever since. Indeed, substantial research has been devoted to understanding why these diseases declined prior to the advent of effective medical care. The two leading hypotheses are that nutritional improvements allowed people to avoid contracting disease and withstand disease once it was contracted (Fogel 1994), and that public health measures reduced the spread of disease (Preston 1996). In each case, preventing disease among some people may limit its spread among others as well. We do not have any additional evidence to bring to bear on this issue. Rather, the focus of our analysis is on the transition from this period to later ones.

In contrast to infectious diseases, diseases of old age - cardiovascular disease and cancer most prominently — were increasing over the 1900 to 


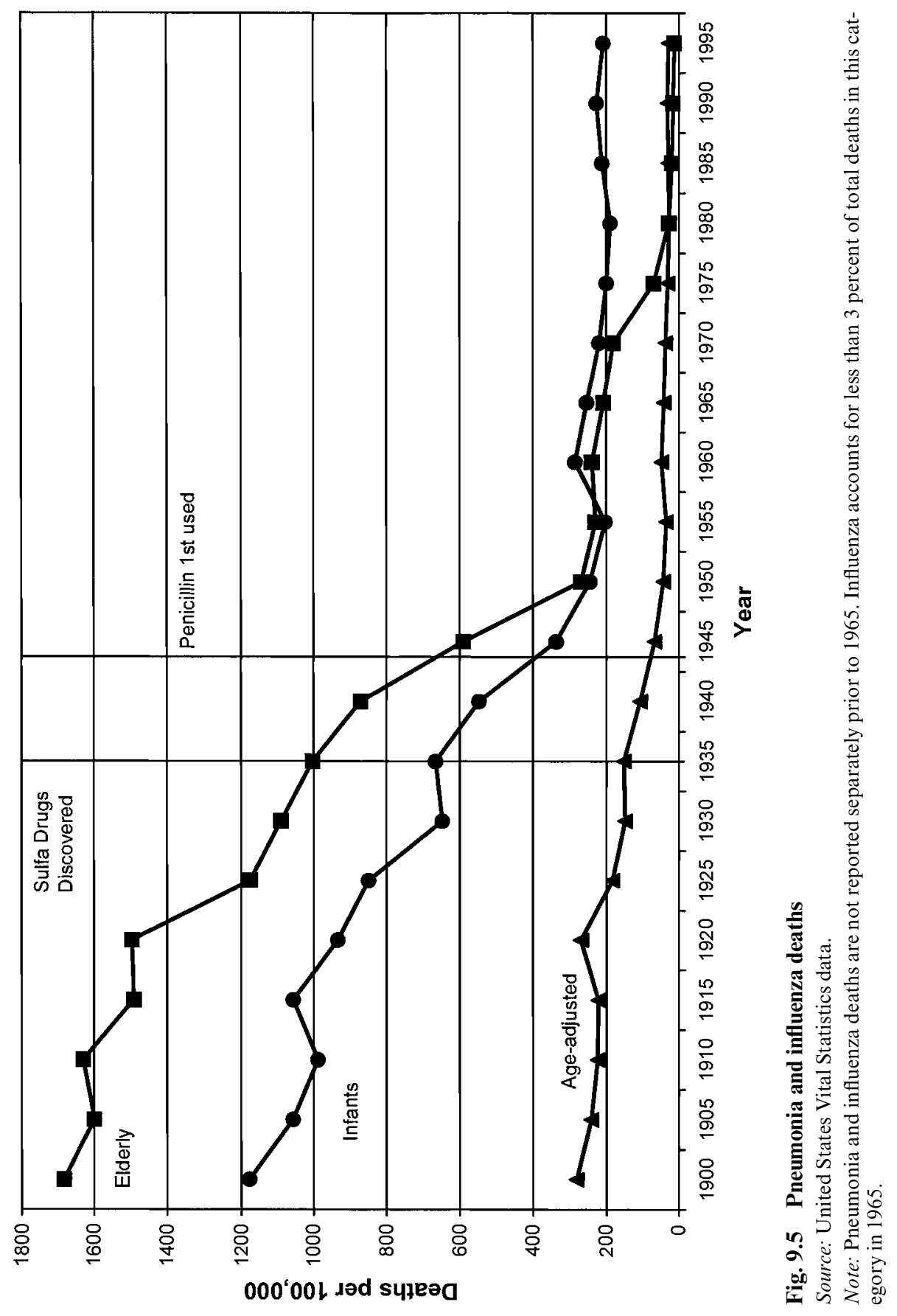




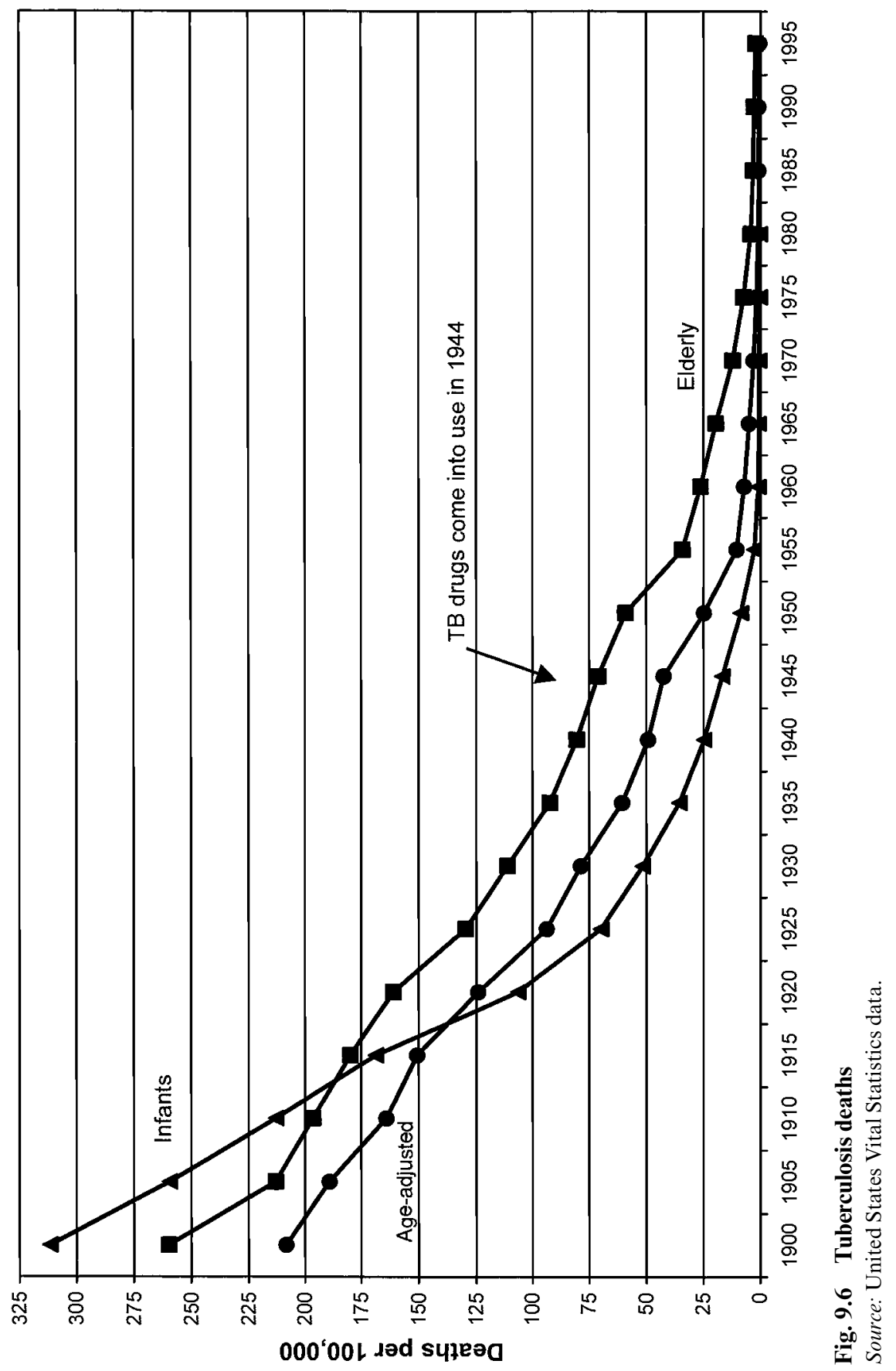




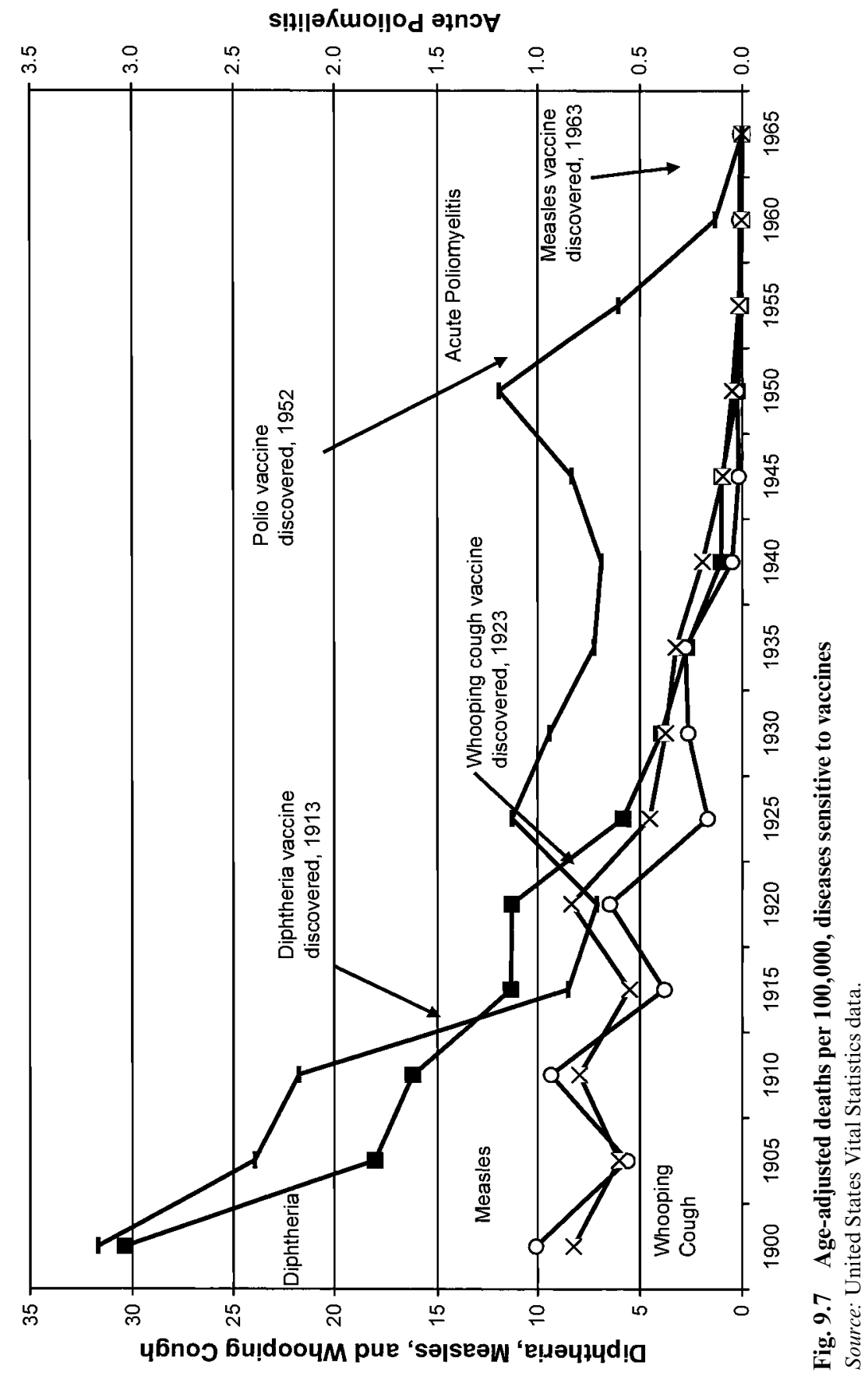


1940 period, as figures 9.8 and 9.9 show. Cardiovascular disease mortality increased by 0.9 percent annually from 1900 to 1940, and cancer mortality increased by 1.2 percent annually. It is not completely known whether the increase in cardiovascular disease mortality results from better diagnosis or a true rise in cardiovascular deaths, but it is believed by most to be at least partly a true increase. We know, for example, that smoking rates were increasing over this time period and smoking is a leading risk factor for cardiovascular disease and cancer. Thus, there are identifiable factors that would lead to increased mortality for these conditions.

The net effect is that cardiovascular disease accounted for 22 percent of mortality in 1900 but 44 percent of deaths in 1940. Cancer accounted for 5 percent of total deaths in 1900 and 11 percent of deaths in 1940.

\subsection{Midcentury: First Medical Advance}

Even with the dramatic decline in mortality from infectious diseases between 1900 and 1940, infectious diseases were still prominent killers in 1940. Thirteen percent of deaths resulted from infectious disease in 1940, more than cancer but far below the now dominant cardiovascular disease.

Infectious disease mortality continued its substantial decline in the 1940-60 time period. Between 1940 and 1960, deaths due to infectious disease declined 5.7 percent per year, well above the 3.2 percent annual rate between 1900 and 1940. In total, the decline in infectious disease mortality accounted for 34 percent of the total decline in mortality in this period.

What is different about the decades in midcentury is the growing importance of medical care in this mortality decline. Midcentury saw the development and widespread diffusion of drugs to treat many infectious diseases, most importantly sulfa drugs and penicillin. These drugs are used most prominently in treating pneumonia but also other infectious diseases as well. Following the introduction of sulfa drugs and penicillin, mortality for conditions where penicillin is effective declined particularly rapidly. For example, pneumonia and influenza deaths declined at an annual rate of 2.4 percent per year between 1900 and 1940, but by 3.9 percent per year between 1940 and 1960. As figure 9.5 shows, the timing of the more rapid mortality reduction is coincident with the development of these medications. It is therefore a reasonable inference that medical innovation explains part of this more rapid decline.

We can be more formal about this conclusion. Because we believe that much of the decline in pneumonia and influenza before 1940 stemmed from better nutrition and public health measures, one way to more formally test whether penicillin and sulfa drugs had a significant impact on these diseases is to compare pneumonia and influenza mortality to another disease or set of diseases that are sensitive to public health and nutrition, but not sensitive to penicillin or sulfa drugs. Dysentery, enteritis, and 


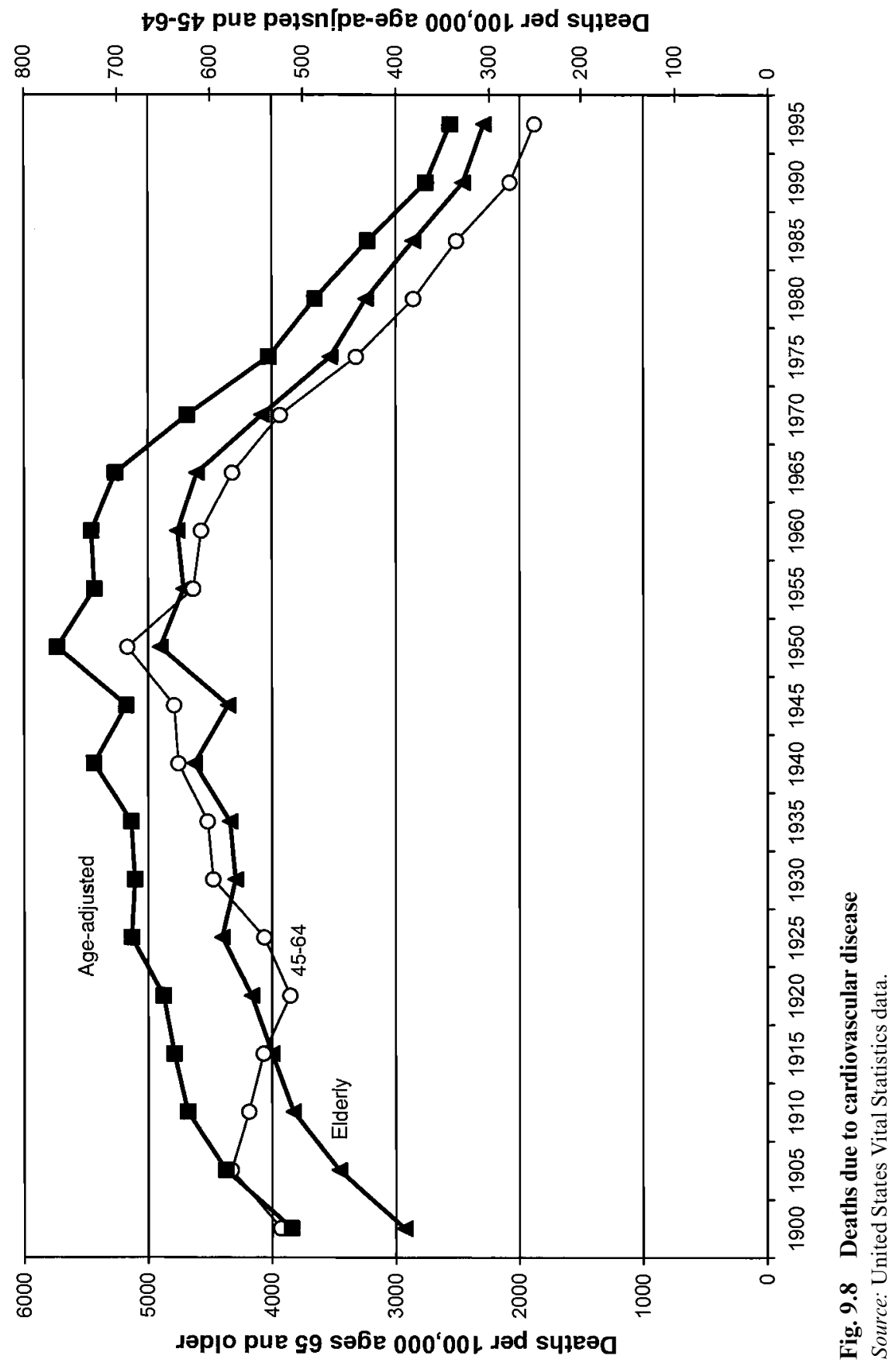




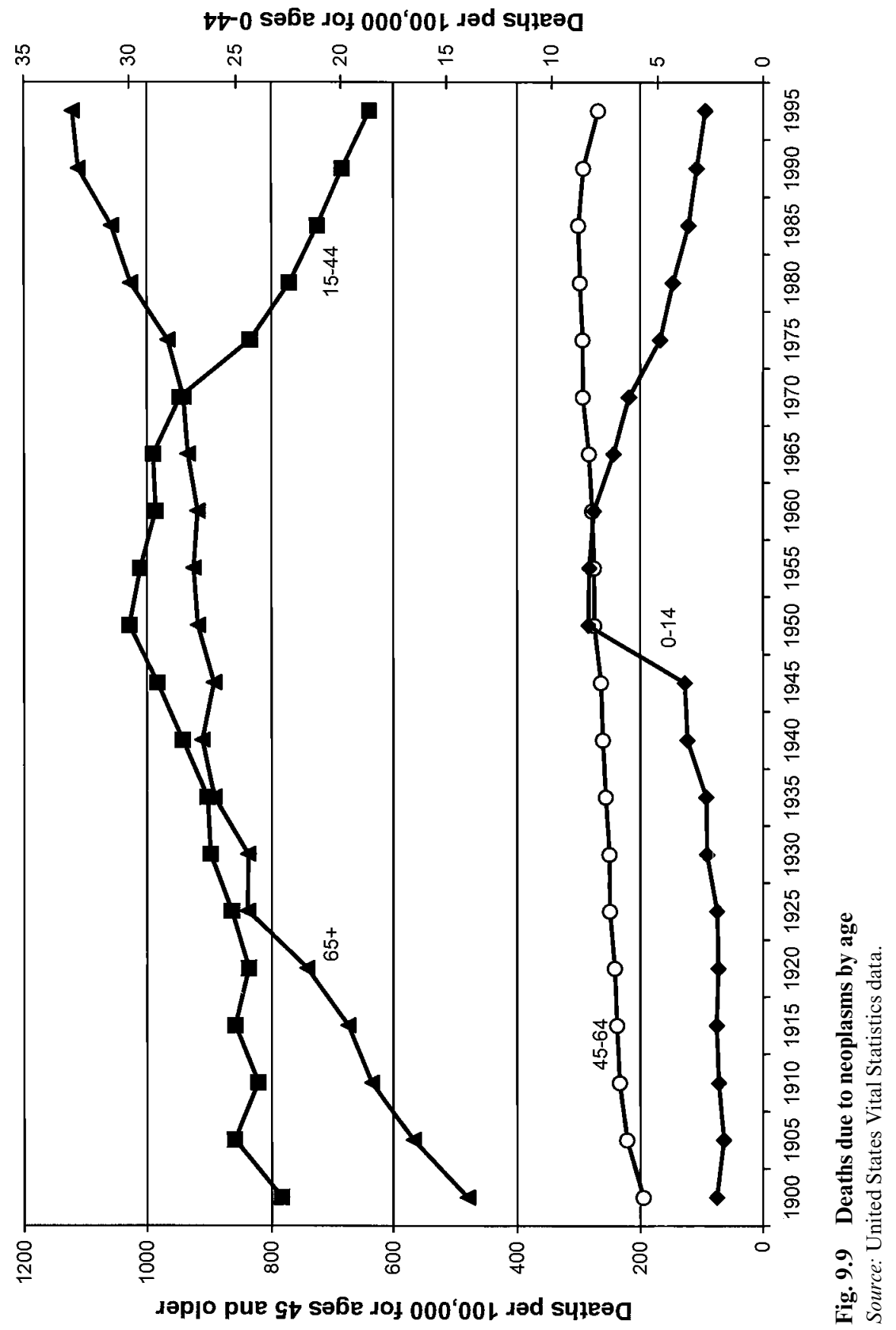


Table 9.4

\begin{tabular}{lccc}
\hline \multicolumn{4}{c}{ Annual Change in Mortality } \\
\hline & $\begin{array}{c}\text { Before Sulfanomides } \\
\text { and Penicillin } \\
(1915-1935)\end{array}$ & $\begin{array}{c}\text { After Sulfanomides } \\
\text { and Penicillin } \\
(1945-1965)\end{array}$ & Difference \\
Disease & -1.9 & -2.4 & -0.5 \\
$\begin{array}{l}\text { Pneumonia/influenza } \\
\text { Dysentery, enteritis, } \\
\text { diarrheal disease }\end{array}$ & -6.1 & -2.8 & 3.3 \\
Difference-in-difference & & & -3.8 \\
\hline
\end{tabular}

Note: Because death rates are based on entire U.S. population, standard errors are negligible and therefore omitted.

diarrheal diseases provide such an example because these diseases are largely viral and thus do not respond to antibiotics. Individuals with better nutrition will be more resistant to these diseases, and better sanitation, cleaner water supply, and better hygiene in general helps to prevent the spread of these diseases.

Table 9.4 shows a simple difference-in-difference calculation of the trend in deaths due to these diseases during the twenty years before and twenty years after the advent of sulfanomide drugs and penicillin. Deaths due to dysentery, enteritis, and diarrheal diseases declined in both time periods but much more rapidly during the 1915-35 time period than the 1945-65 time period. The slowdown in the rate of decline was 3.3 percent per year. In contrast, deaths due to pneumonia and influenza witnessed a more rapid decline during the postantibiotic period, by 0.5 percent per year. If one believes that deaths due to these diseases would have experienced similar declines in the absence of antibiotics, this difference-in-difference of 3.8 percent per year following antibiotics suggests that antibiotics did significantly impact mortality.

This conclusion also finds support in the literature. McDermott (1978) noted the rapid decline in infectious disease mortality after 1937 and attributed it to pharmaceutical advance as well.

Other important diseases declined significantly midcentury, and medical care plays a clear role in these cases as well. For example, chronic nephritis accounted for 13 percent of deaths in 1940, but declined 4.7 percent per year until 1960. This decline alone accounts for 32 percent of the decline in total mortality. Figure 9.10 shows deaths from nephritis over time. The decline in mortality from kidney disease is coincident with the advent of kidney dialysis in the United States in 1948. While there was a small decline in deaths from kidney disease in the late 1920s and 1930s, the rate of mortality decline increased dramatically in the 1940s. 


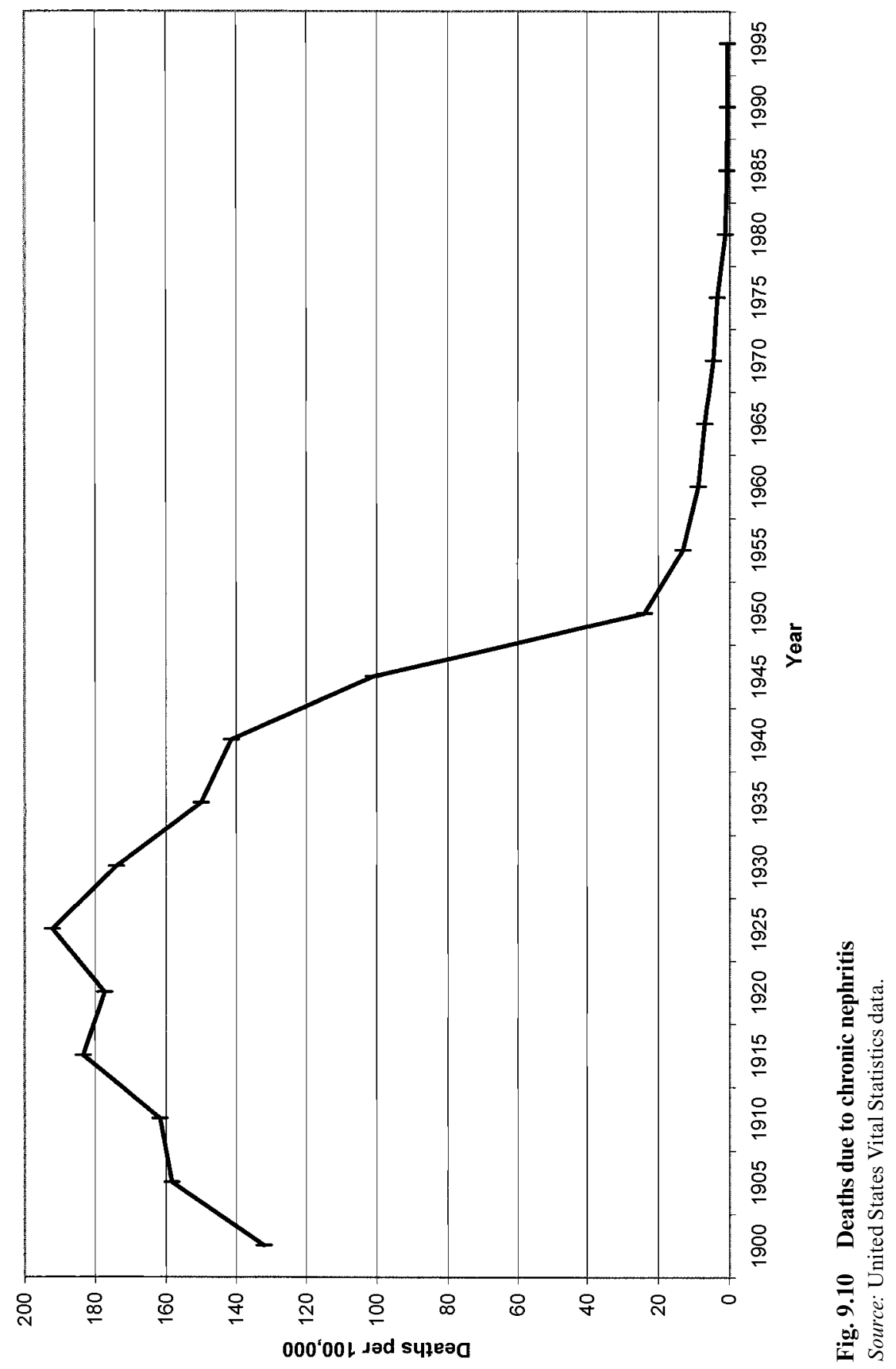




\subsection{The Later Decades: Cardiovascular Disease and Low Birth Weight Infants}

By 1960, infectious disease mortality was extremely low. The cumulative decline in infectious disease deaths from 1900 to 1960 was 92 percent. And even though infectious disease mortality continued to decline, further declines did not contribute greatly to overall improvements in life expectancy at birth. After all, even a large decline in mortality from a cause that does not kill many people has little impact on overall longevity. The leading killers in 1960 were cardiovascular disease (59 percent of the total) and cancer (15 percent of the total). Infectious disease mortality was only 5 percent of total mortality.

It was around this time that mortality reductions as a whole slowed. Between 1955 and 1965, overall mortality was flat. The already low level of infectious disease mortality, combined with the lack of progress in mortality from the chronic diseases of old age, was a leading reason for this. The realization that the traditional killers had largely been eliminated led to pessimism about future improvements in longevity. It was feared that technological progress had done all for health that it was able to do and that the limits of longevity had been reached. Famed biologist Rene Dubos was among those who believed that "Modern medicine has little to offer for the prevention or treatment of chronic and degenerative diseases that dominate the pathological picture of technologic societies" (Dubos 1969, 328).

Beginning in the mid-1960s, though, cardiovascular disease mortality began to decline. The decline, shown in figure 9.8, was rapid, about 2 percent per year through the end of the century. The cumulative decline in cardiovascular disease mortality between 1960 and 1995 was close to twothirds.

Cardiovascular disease is most prominent among the elderly, so the mortality gains were concentrated there. Indeed, cardiovascular disease is so prominent among the elderly that the decline in cardiovascular disease mortality explains essentially all of the overall reduction in mortality for the elderly since 1965 . For the population as a whole, 98 percent of mortality reductions between 1960 and 1990 were a result of reduced cardiovascular disease mortality.

There are several causes of reduced cardiovascular disease mortality. Cutler and Kadiyala (2001) document the sources and provide a rough attribution. According to their findings, medical care accounts for a relatively large share of cardiovascular disease mortality reduction. A major component of such care is high-tech medical interventions for the treatment of acute heart disease, particularly heart attacks. These interventions include drugs to dissolve blood clots and restore blood flow to the heart, surgical procedures such as bypass surgery and angioplasty, and specialized equipment such as coronary care units and trained emergency re- 
sponse teams. A related component is low-tech medical care, largely pharmaceuticals. Medications to reduce blood pressure, manage cholesterol, control the heart rhythm, reduce the heart's workload in times of stress, and similar goals have reduced mortality for patients with heart disease and prevented serious occurrences of heart disease for patients who have not yet experienced a severe episode.

Cutler and Kadiyala (2001) also highlight the importance of behavioral changes. Principal among these is the reduction in smoking. As figure 9.11 shows, smoking rates fell after 1960, after six decades of continuous increase. Between 1960 and 1990, the number of cigarettes smoked declined by one-third. Reductions in fat intake have also played a role in better health.

This decomposition of mortality reductions for cardiovascular disease is not as accurate as one would like. Issues such as changes in childhood disease and birth weight, which may affect cardiovascular disease in later life, are not explicitly accounted for. Still, even this rough decomposition of mortality makes clear the growing medicalization of better health. A significant part of reduced mortality is directly attributable to medical interventions, either for acute disease or in a chronic setting. Another large part is behavioral, but has roots in medical knowledge about the origins of disease.

Indeed, the medicalization of mortality reduction extends even to ages where medicine traditionally had a very small role. It was noted earlier, for example, that infant mortality reductions contributed to improved life expectancy at birth in the 1960 to 1990 time period just as they did in the pre1960 time period. But the nature of these changes after 1960 was very different.

Figure 9.12 divides infant mortality into two components: neonatal mortality, or death in the first twenty-eight days of life; and postneonatal mortality, or death in the subsequent eleven months. In the first half of the century, postneonatal mortality declines were substantially more important than neonatal mortality declines. Between 1915 and 1960, postneonatal mortality declined by 4.4 percent per year, compared to a 1.9 percent annual decline in neonatal mortality. Postneonatal mortality is generally attributable to the infectious diseases noted previously, so this is consistent with the aggregate evidence on mortality change.

Since 1960, however, most of the decline in infant mortality has been in neonatal mortality. In the 1960 to 1998 period, neonatal mortality declined by 3.5 percent annually, compared to 2.9 percent for postneonatal mortality. Death in the first month of life is generally not a result of infectious disease. It is predominantly due to low birth weight and the adverse consequences of low birth weight for infant development. In fact, our earlier analysis of the issue (Cutler and Meara 2000) suggested that essentially all of the reduction in neonatal mortality since 1960 can be attributed to medical progress. 


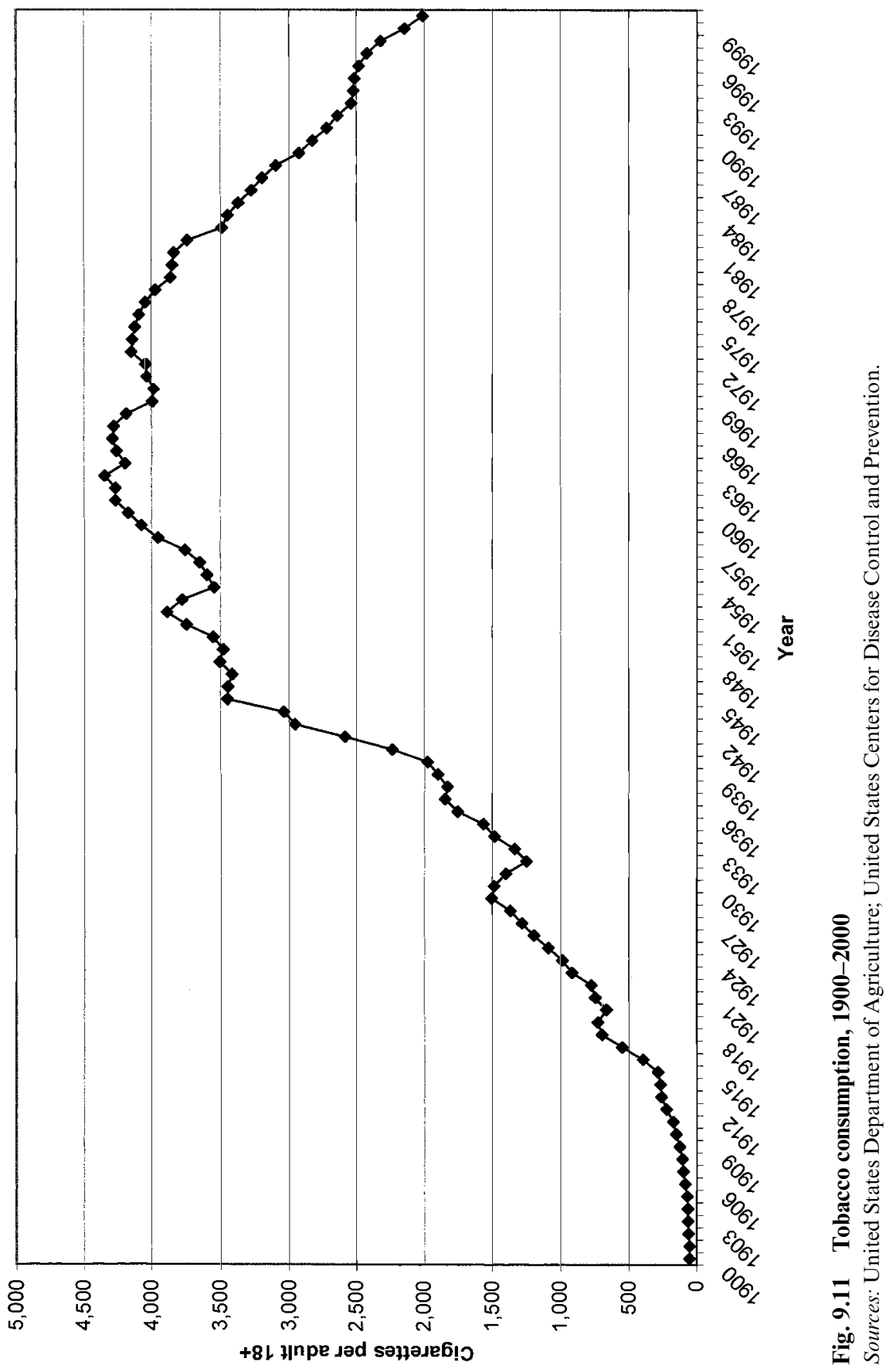




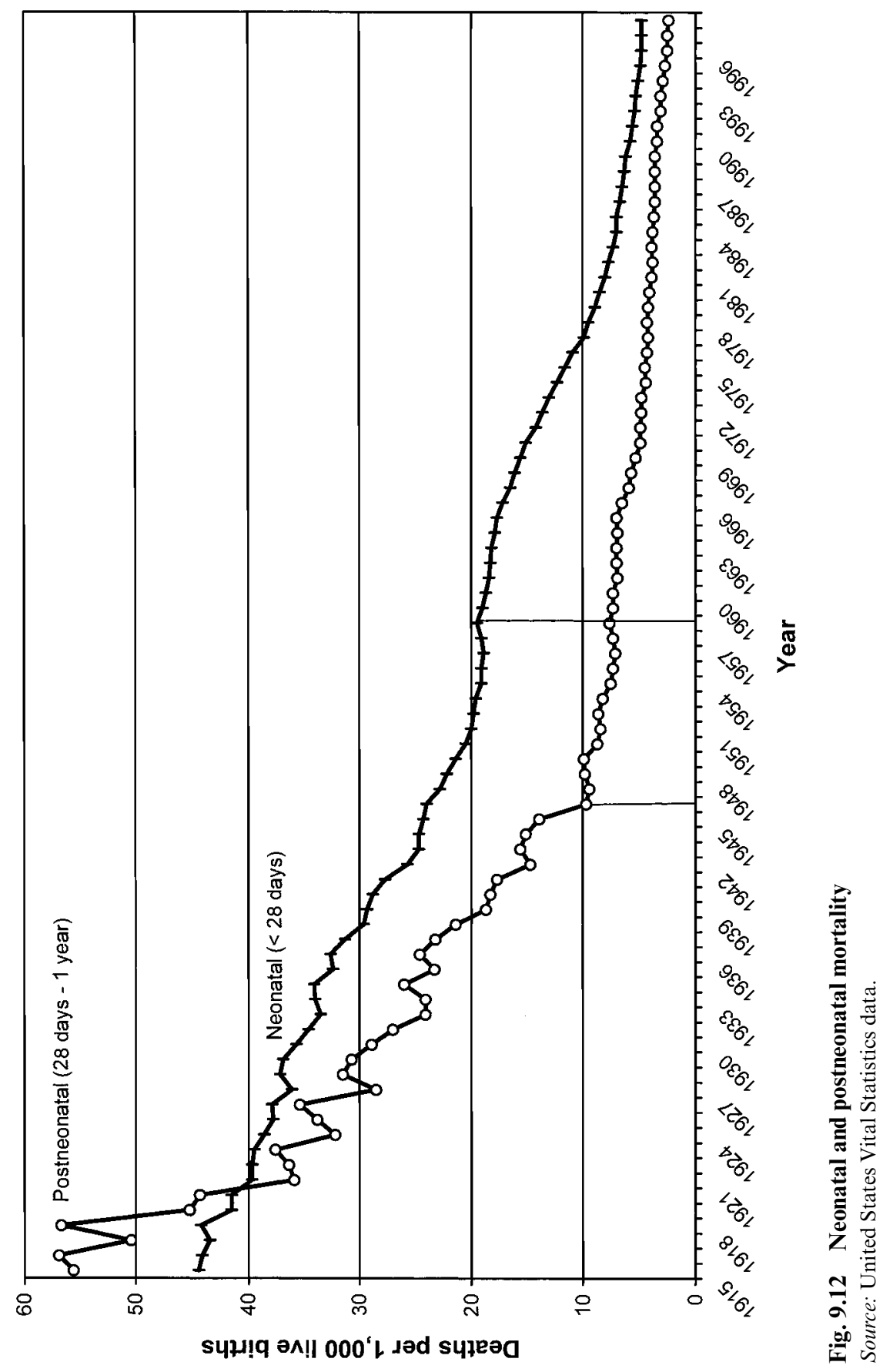


The decline in mortality in the latter part of the twentieth century therefore seems attributable in substantial measure to medical progress. That is very different from the reasons why mortality declined earlier in the century and has enormous implications for the value of medical care.

\subsection{Other Factors Influencing Mortality}

Still, medicine is not the only factor influencing health. Understanding mortality reductions requires us to disentangle many different causes. We discuss in this section several additional causes of mortality reduction and some evidence on their importance. The logical next step-estimating how important the different factors are-we leave to future work.

\subsubsection{Behavior}

Some behaviors promote health and others worsen it. Behavioral change is a key component of health changes. The most significant behavioral change of the twentieth century was the rise and decline of smoking. Figure 9.11 shows smoking trends over the century. From essentially no cigarette consumption in 1900, per capita consumption of cigarettes rose to over 4,000 per year in 1960, or over two packs per smoker per day. Since then, cigarette consumption has declined to about 2,000 per year, a reduction of over 50 percent.

The most important health consequences of smoking are heart disease and cancer, particularly cancer of the lung, thorax, and bronchus. ${ }^{2}$ The trend in cardiovascular disease mortality was discussed above. The trend in smoking-sensitive cancers is shown in figure 9.13. Trends in mortality from both of these conditions mirror the change in smoking, with a ten- to twenty-year lag.

\subsubsection{Socioeconomic Status}

Socioeconomic status may affect health in several ways. Medical technology is expensive, and income increases have been instrumental in financing that care. Further, socioeconomic status is associated with better behaviors. Better educated, and thus richer, people smoke less than less educated people (at least currently - they used to smoke more), perhaps because they know more about the true risks of disease. Education has a slightly stronger relationship to smoking than income, but this could be either because education truly matters more or because education picks up measures of permanent income not well captured by current income in most surveys on smoking.

But there are other links as well. Richer people may demand better

2. While many cancers are attributable in some part to smoking, smoking accounts for the greatest share of these three cancers. 


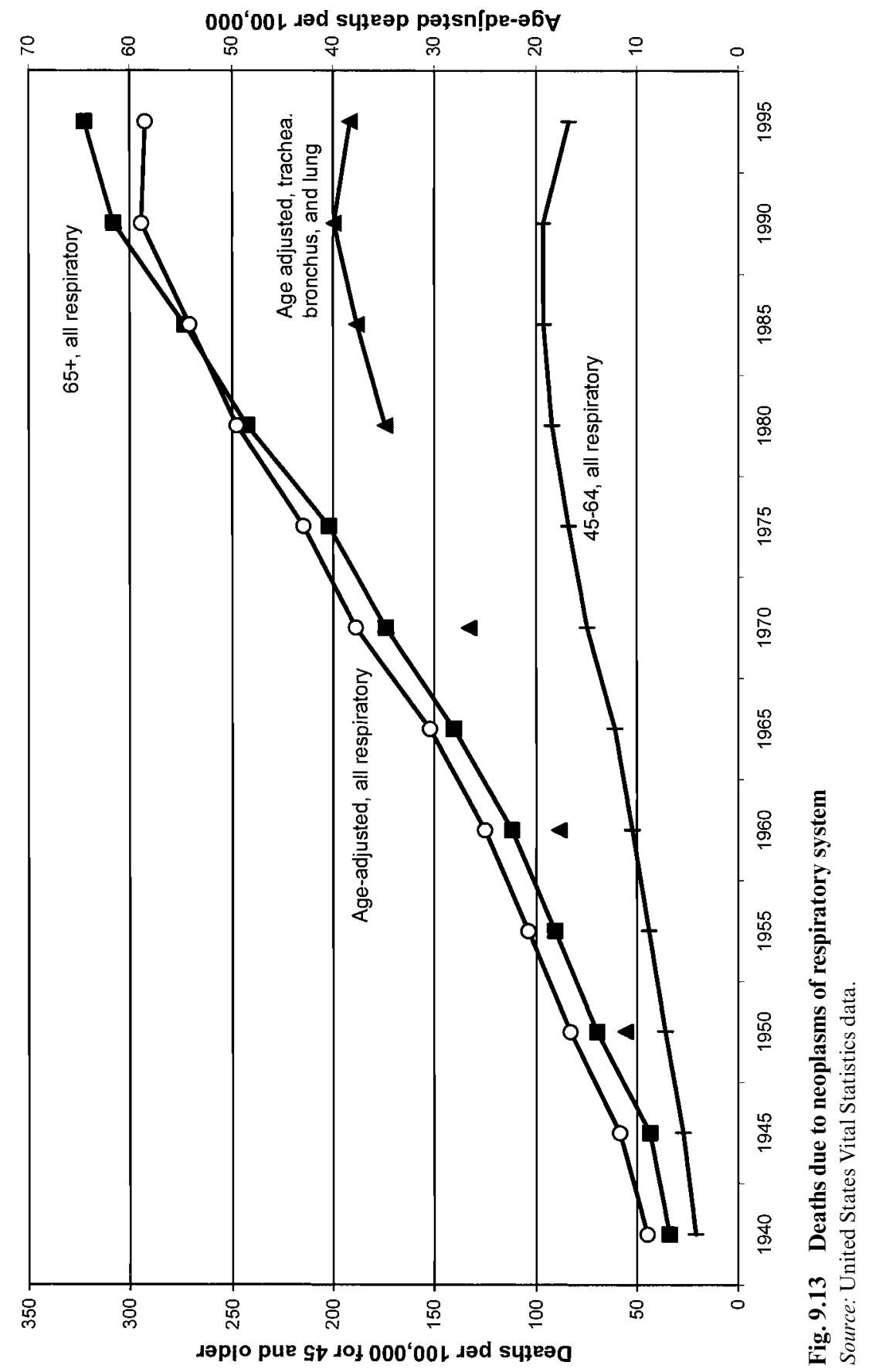


health, just as there is an income elasticity to many goods. The link between behavior and education suggests such an effect. Some direct evidence on this question comes from looking at suicide rates, shown in figure 9.14. Since 1930, suicide rates among the elderly have fallen by 56 percent, while rates among teens have tripled. The decline in suicide among the elderly is coincident with the large absolute increase in income for the elderly stemming from transfer programs such as Social Security and the programs that preceded it. Following the introduction of formal Social Security benefits, benefits rose rapidly over the period from 1950 until 1970, with a particularly rapid rise in the late 1960s. During these same time periods, suicide rates among the elderly fell most rapidly. It is less clear that the rise in youth suicide reflects falling income, although it may be due to other social pressures that are influencing youths (Cutler, Glaeser, and Norberg 2001).

Finally, income may affect health in other, indirect ways. A large literature on income inequality and health finds a correlation between adverse health outcomes and high levels of income inequality, even after controlling for mean income (Wilkinson 1996; Berkman and Kawachi, 2000). This literature has been questioned as being not particularly robust (Mellor and Milyo 2001) and as inconsistent with posited mechanisms for action (Deaton 2001). Overall, therefore, it is difficult to tell if this mechanism is important in practice.

Some of the most compelling research on social status and health comes from the Whitehall study of British civil servants (Marmot et al. 1984, $1987,1991)$. In a series of studies following civil servants over time, it has been well documented that professionals in the British civil service experience better health than their counterparts in lower-level occupations within the civil service. This is true for mortality and a variety of health measures related to cardiovascular disease and other major morbidities. It is also true for risk factors such as smoking, sedentary lifestyle, and related behavioral variables, although these lifestyle factors cannot explain the entire difference in health outcomes across occupation. As income gaps widen over time, disparities in health have also widened (Menchik 1993).

\subsubsection{Social Policies}

Social policy is a third additional factor influencing mortality. Social policy is a vast term, and it is helpful to disaggregate it. Some social policies are clearly oriented to health improvements. Medicare and Medicaid are prime examples. Both programs were designed to increase access to health care for vulnerable populations, the elderly, and the poor, with the ultimate goal of improving health for these groups.

Other social policies such as Social Security affect income and may affect health through that channel. Income may have direct effects on health by increasing the purchase of medical care services and financing 


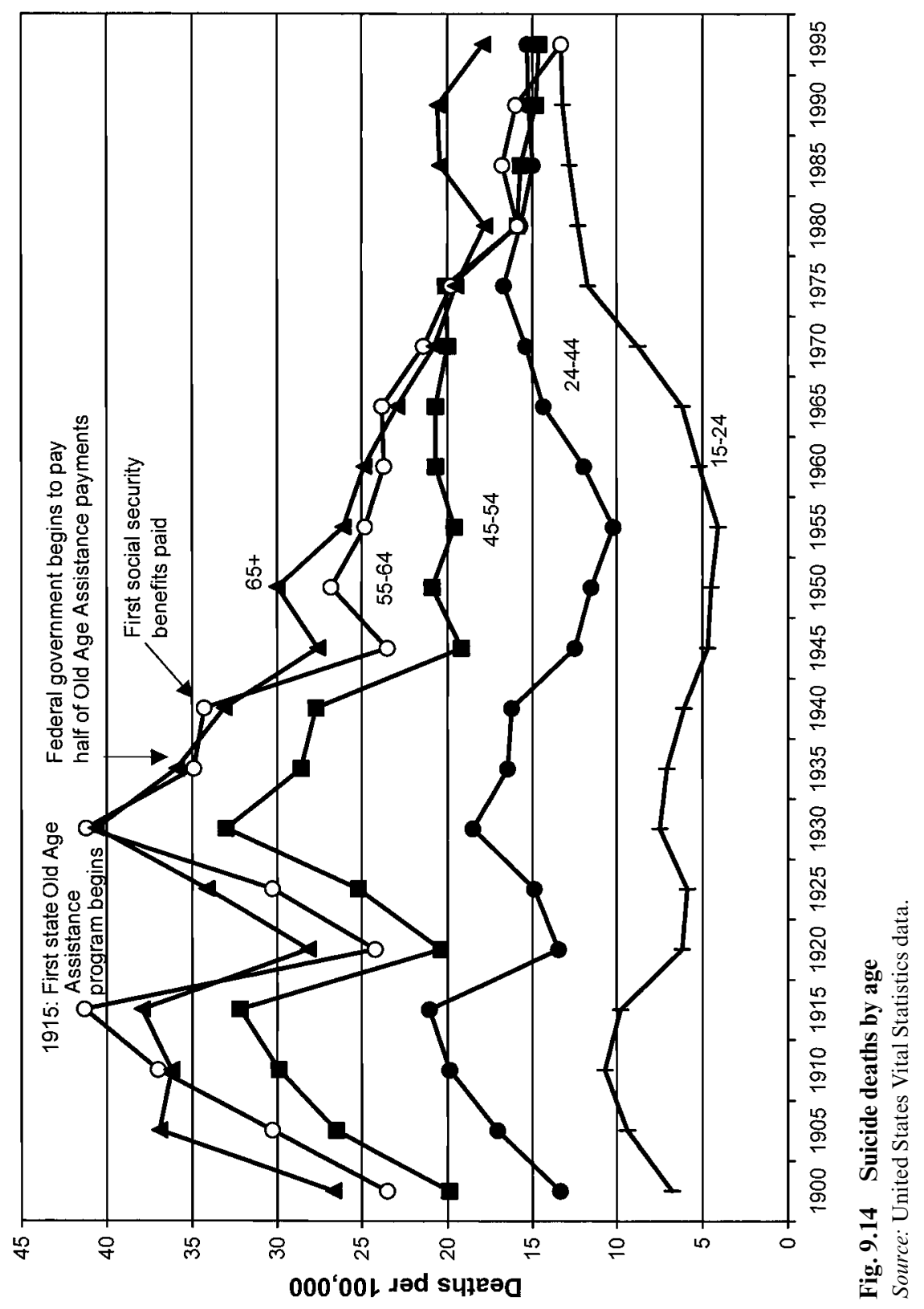


consumption of items such as nutritious food that contributes to good health, or indirect effects by increasing the desire for healthy behaviors to enjoy a longer and higher quality life. It may be difficult to measure the precise impact of Social Security benefits on overall health, but evidence, such as that presented on suicide in figure 9.14, suggests that income benefits can have a substantial impact on the well-being of the elderly.

Finally, some social policies may affect health by changing the access that people have to already-established resources. One example of such policies would be the combination of civil rights legislation and improved health programs for the poor during the mid-1960s, especially through Medicaid. Ongoing work by Almond, Chay, and Greenstone (2001) suggests that the Civil Rights Act, along with expansions in the Medicaid program, led to substantial improvements in access to care, and ultimately in health outcomes for the poor. They show this by comparing white and nonwhite infant mortality disparities over time, presented in figure 9.15.

There is a clear decline in the ratio of nonwhite to white infant mortality following the 1966 Civil Rights Act. However, the considerable change in the nonwhite to white ratio of infant deaths over the century suggests that there are many factors that influenced health differentially for the different races. For example, the period during World War II shows a big fall in the ratio of nonwhite to white infant mortality. This shrinking infant mortality gap mirrors the shrinking racial wage gaps that occurred during World War II. It is also interesting to note that the ratio of nonwhite to white infant mortality is higher during the last decade of the century than at any other point in the past 100 years.

\subsection{Conclusion}

Mortality has declined continuously in most developed countries over the course of the twentieth century. In the United States, mortality rates declined every decade, and with the exception of a single ten-year period, did so at relatively constant rates.

But the constancy of mortality reductions masks significant heterogeneity by age, cause, and source. Early in the twentieth century, mortality declines resulted from public health and economic measures that improved peoples' ability to withstand disease. Formal medical care was unimportant for longer life. Because nutrition and public health were more important for the young than the old, mortality reductions were concentrated at younger ages. By midcentury, medical care became more significant and other factors less so. Penicillin and sulfa drugs brought the first mortality reductions at older ages, which were coupled with continuing improvements in health at younger ages. The pattern of mortality reduction was relatively equal by age.

In the latter part of the twentieth century, death became increasingly 


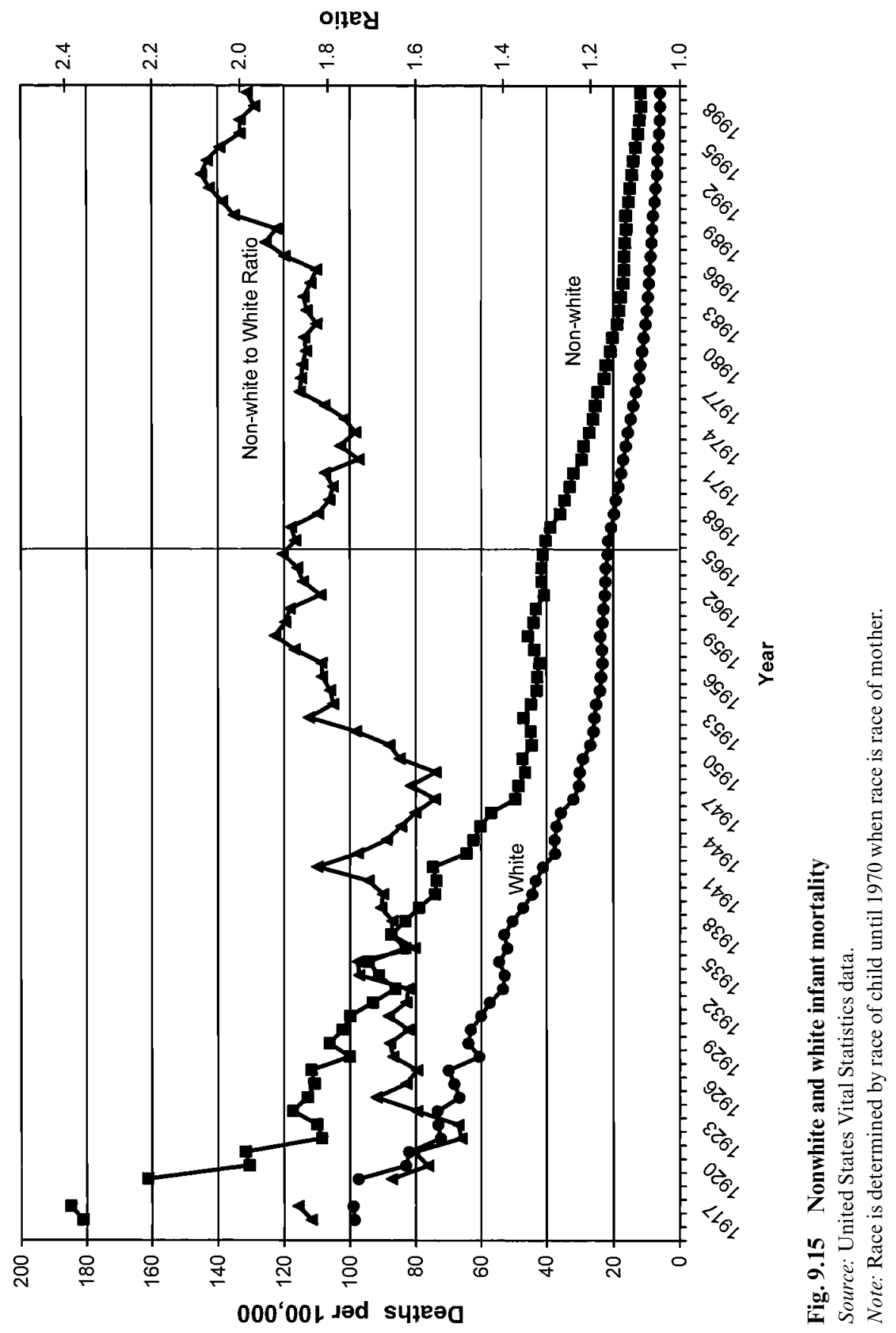


medicalized. Cardiovascular disease mortality was prevented in significant part through medical intervention. Traditional killers such as pneumonia in the young continued to decline, but mortality from these causes was already so low that further improvements did not add greatly to overall longevity. Rather, infant mortality declined because medical advances kept alive infants born of low birth weight. Still, there was a significant shift in the nature of longevity improvements away from improvements at younger ages and toward improvements at older ages. Most of the additional years added to life in the last few decades of the twentieth century were at older ages.

Medical care is an important, but not the only important, factor in reduced mortality. In addition to nutrition and public health, health insurance programs, income changes, and social policies more generally have all contributed to longer life. Disentangling the role of these different factors in reduced mortality is a difficult task but one that is increasingly important in light of the vast fiscal consequences of an aging society.

\section{References}

Almond, Douglas, Kenneth Chay, and Michael Greenstone. 2001. Civil rights, the war on poverty, and black-white convergence in infant mortality in Mississippi. University of California, Berkeley. Mimeograph.

Berkman, Lisa, and Ichiro Kawachi, eds. 2000. Social epidemiology. New York: Oxford University Press.

Cutler, David, Edward Glaeser, and Karen Norberg. 2001. Explaining the rise in youth suicide. In Risky behavior among youths, ed. Jonathan Gruber, 219-69. Chicago: University of Chicago Press.

Cutler, David, and Srikanth Kadiyala. 2001. The economics of better health: The case of cardiovascular disease. Harvard University. Mimeograph.

Cutler, David, and Ellen Meara. 2000. The technology of birth: Is it worth it? In Frontiers in health policy research, Vol. 3, ed. Alan Garber, 33-67. Cambridge, Mass.: MIT Press.

Deaton, Angus. 2001. Relative deprivation, inequality, and mortality. NBER Working Paper no. 8099. Cambridge, Mass.: National Bureau of Economic Research, January.

Dubos, Rene. 1969. The Diseases of Civilization. Milbank Memorial Fund Quarterly, 47:327-29.

Fogel, Robert W. 1994. Economic growth, population theory, and physiology: The bearing of long-term processes on the making of economic policy. American Economic Review (84): 369-95.

Lee, Ronald, and Lawrence Carter. 1992. Modeling and forecasting U.S. mortality. Journal of the American Statistical Association 87 (419): 659-71.

Marmot, Michael, M. Kogevinas, and M. A. Elston. 1987. Social/economic status and disease. Annual Review of Public Health 8:111-35.

Marmot, Michael, M. J. Shipley, and G. Rose. 1984. Inequalities in death-specific explanations of a general pattern? Lancet 1 (8384): 1003-06. 
Marmot, Michael, G. D. Smith, S. Stansfeld, C. Patel, F. North, J. Head, I. White, E. Brunner, and A. Feeney. 1991. Health inequalities among British civil servants: The Whitehall II Study. Lancet 337 (8754): 1387-93.

McDermott, Walsh. 1978. Medicine: The public good and one's own. Perspectives in Biology and Medicine 21 (2): 167-87.

McKeown, Thomas. 1976. The modern rise of population. New York: Academic Press.

McKeown, Thomas, R. G. Record, and R. D. Turner. 1975. An interpretation of the decline of mortality in England and Wales during the twentieth century. Population Studies 29:391-422.

Mellor, Jennifer, and Jeffrey Milyo. 2001. Income inequality and health. Journal of Policy Analysis and Management 20 (1): 151-55.

Menchik, Paul L. 1993. Economic status as a determinant of mortality among black and white older men: Does poverty kill? Population Studies 47 (3): 427-36.

Preston, Sam. 1996. American longevity: Past, present, and future. Syracuse University Policy Brief no. 7/1996. Distinguished Lecturer in Aging Series. Syracuse, N.Y.: Syracuse University, Center for Policy Research.

Wilkinson, Richard. 1996. Unhealthy societies. London: Routledge. 
